\title{
Chronic renal failure; an important feature of the Laurence-Moon-Biedl syndrome
}

\author{
Bryan Williams, David Jenkins and John Walls
}

The Department of Nephrology, Leicester General Hospital, Leicester LE5 4PW, UK.

\begin{abstract}
Summary: Two cases of end stage renal failure occurring in association with the LaurenceMoon-Biedl syndrome are reported. Abnormalities in renal function and morphology are increasingly recognized in these patients in whom uraemia is an important cause of morbidity and early mortality. The presence of renal impairment, occurring as frequently as any of the pentad of features that characterize the syndrome, has important implications for the prognosis and long term management of these patients.
\end{abstract}

\section{Introduction}

Laurence-Moon-Biedl syndrome is a rare congenital disorder, inherited by an autosomal recessive characteristic with variable penetrance and expressivity. The syndrome is characterized by five cardinal features, obesity ( $85 \%$ of cases), mental retardation $(80 \%)$, polydactyly $(75 \%)$, retinitis pigmentosa $(68 \%)$ and hypogenitalism $(60 \%){ }^{1}$ Less than $50 \%$ of cases show the complete pentad and males are more commonly affected than females. Recent reports suggest that functional and morphological renal abnormalities are present in up to $90 \%$ of affected patients. ${ }^{2,3,4}$ The renal involvement occurs with a spectrum of activity, often causing significant morbidity and autopsy data reveals it to be the major cause of death., ${ }^{3,6}$ It is suggested that renal disease should be considered as an additional, sixth cardinal feature of the LaurenceMoon-Biedl syndrome. ${ }^{3,7,8}$ Two further cases are reported to lend support to this concept and to illustrate that such patients should not be denied renal replacement therapy.

\section{Case reports}

\section{Case 1}

A 37 year old male patient presented as a medical emergency in August 1986. At age 10 years a diagnosis of Laurence-Moon-Biedl syndrome had been established on the presence of polydactyly, deteriorating vision due to retinitis pigmentosa, mental retardation (I.Q. 68), obesity and hypo-

Correspondence: J. Walls, F.R.C.P.

Accepted: 20 January 1988 gonadism. Polyuria had been recorded but no urinalysis was performed. A year later corrective surgery was performed to both hands and feet with a good cosmetic and functional result. At 15 years he was registered blind, became resident in supervised accommodation for the blind and appeared healthy. One week prior to admission he had become irritable, nauseated and increasingly dyspnoeic. On admission he was comatose with a blood pressure of $140 / 90 \mathrm{~mm} \mathrm{Hg}$. Pulmonary oedema, minimal peripheral oedema and a pericardial friction rub were present. No abdominal organs were palpable. The urine sediment showed 80 red blood cells and 100 white blood cells per high power field but no casts. Urine culture grew significant numbers of coliform bacilli. Investigations showed: serum sodium $149 \mathrm{mmol} / 1$, potassium $8.3 \mathrm{mmol} / \mathrm{l}$, urea $83 \mathrm{mmol} / \mathrm{l}$, creatinine $1866 \mu \mathrm{mol} / \mathrm{l}$, calcium $1.66 \mathrm{mmol} / \mathrm{l}$, phosphate $3.9 \mathrm{mmol} / \mathrm{l}$ and fasting blood sugar $3.2 \mathrm{mmol} / \mathrm{l}$, arterial pH 6.73, $P_{C_{2}} 2.5 \mathrm{~mm} \mathrm{Hg}, P_{2} 11 \mathrm{~mm} \mathrm{Hg}$ and bicarbonate $2.5 \mathrm{mmol} / \mathrm{l}$, haemoglobin $8.5 \mathrm{~g} / \mathrm{dl}$ (normochromic, normocytic) white blood cells $11 \times 10^{9} / 1$, platelets $284 \times 10^{9} / 1$. Autoimmune screen negative, hepatitis B surface antigen positive. Renal ultrasound revealed bilateral small kidneys ( 7.0 and $7.5 \mathrm{~cm}$ ) with irregular outlines and marked cortical loss. Small cysts were seen within the left kidney. In September 1986 the patient was commenced on twice weekly haemodialysis in the Renal Isolation Unit. Initially a subclavian catheter was used for vascular access and a forearm arterio-venous fistula was surgically constructed which thrombosed postoperatively, but a second was successfully constructed in the other forearm. During this

(C) The Fellowship of Postgraduate Medicine, 1988 
period the patient was admitted to hospital for two days for treatment of a staphylococcal septicaemia originating from the subclavian catheter. He has since remained well and has required no further hospital admissions. He is fully rehabilitated and lives independently in supervised accommodation, working part time as a basket weaver. After virological assessment of his hepatitis B status, he has recently been accepted onto the renal transplantation waiting list.

\section{Case 2}

A 30 year old female had been diagnosed as a case of the Laurence-Moon-Biedl syndrome at the age of 2 years based on the presence of obesity, a low I.Q. in the 'dull normal' range and supernumerary digits on both hands and feet which were subsequently surgically removed. By the age of 12 years her vision was deteriorating and the presence of retinitis pigmentosa was noted; 13 years later she was registered blind. She enjoyed good general health and remained in full time employment performing simple clerical tasks until her sight failed, thereafter becoming resident in sheltered accommodation for the blind. At the age of 25 years proteinuria was detected. Further investigation showed a non-selective proteinuria of $1.3 \mathrm{~g} / 24 \mathrm{~h}$ and established chronic renal impairment; serum creatinine $305 \mu \mathrm{mol} / \mathrm{l}$, creatinine clearance $11 \mathrm{ml} /$ min. There was no significant urinary sediment, immunological and hepatitis B screening were negative. She was normotensive and has remained so and repeated urine cultures have been sterile. Intravenous urography showed delayed excretion; the left kidney was small and poorly demonstrated. The right kidney was also small with irregular asymmetrical parenchymal reduction and pelvicalyceal clubbing. Her renal function deteriorated relentlessly and in June 1987 she was established on regular unit-based haemodialysis, thrice weekly using a forearm arterio-venous fistula, She has required no hospital admissions since commencing treatment and has remained well. She recently moved from supervised accommodation into her own home and is to be married in March 1988.

\section{Discussion}

The renal abnormalities associated with LaurenceMoon-Biedl syndrome are multiform and progressive. Several reports indicate that a characteristic pattern of urographic, functional and histological abnormalities is emerging. ${ }^{2,3,6,9}$ Urographic abnormalities are present in over $90 \%$ of patients often with apparently normal renal function. A reduction in renal size (although the kidneys continue to grow with age), irregular asymmetrical parenchymal loss, calyceal distortion and clubbing with cortical and medullary cysts are characteristic findings. ${ }^{2,4,8,9,11}$ Renal tubular dysfunction, often predating the onset of uraemia by many years, is also common. Reduction in maximal concentrating capacity is a characteristic feature with aminoaciduria and glycosuria also detected in $50 \%$ of patients in one study. ${ }^{4}$ Of interest, Case 1 reported here was noted to have polyuria and polydipsia at the age of 10 years possibly indicating early tubular dysfunction.

Histological and ultrastructural abnormalities are reported in patients as young as 2 years and in those with normal renal function. ${ }^{12}$ Histological and immunopathological changes range from mesangial proliferation to complete sclerosis of the glomerular tuft. Tubulointerstitial damage with cystic tubular dilatation with cortical and medullary cysts, similar to the changes seen in familial juvenile nephronopthisis also occurs. ${ }^{3,7,10}$ Both tubulointerstitial and glomerular changes are important causes of chronic renal failure in these patients, occurring either independently or as co-existent pathologies, the relationship between the two being unclear.

The occurrence of renal abnormalities in the Laurence-Moon-Biedl syndrome is as frequent as any of the established pentad of cardinal features and there is a significant risk of progression to end stage renal failure. As progressive renal impairment is so common, the prognosis is that of the renal disease which is the major cause of death, usually in the third and fourth decades. Renal function should be assessed early in life and regularly thereafter, with particular emphasis placed on blood pressure control and urine culture. The care of these patients has often been institutionalized which may increase their susceptibility to hepatitis B infection as in Case 1. Such patients with progressive renal impairment should be considered for vaccination against hepatitis B. Once patients require renal replacement therapy, the presence of blindness, a low I.Q., obesity and reduced manual dexterity related to their skeletal abnormalities present a challenge to the dialysis unit and may influence the mode of therapy.

Both of the patients reported here are on unitbased haemodialysis therapy. Although there are no absolute contraindications to the use of chronic ambulatory peritoneal dialysis, the presence of visual impairment would require a committed partner to regularly perform the peritoneal fluid exchanges using an aseptic technique. As many of these patients are unmarried and live independently in sheltered or supervised accommodation such constant individual attention is unlikely to be 
available. Home haemodialysis would require a similar commitment. Therefore unit-based haemodialysis would seem to be the most appropriate option. Both patients have adapted well to haemodialysis and are fully rehabilitated back into the community. After their initial inpatient stay during which the patients were established on treatment, neither has required any hospital admissions during the 21 patient-months of hospital haemodialysis treatment. This contrasts with recent data from a multicentre study which suggested that the mean requirement for inpatient admission of any dialysis patient established on treatment was approximately 2 weeks per year. ${ }^{13}$

The two patients reported here manifest a majority of the five accepted cardinal features of the Laurence-Moon-Biedl syndrome. In addition,

\section{References}

1. Smith, D.W. Recognisable patterns of human malformation. W.B. Saunders, Philadelphia, 1970, pp 86-87.

2. Bauman, M. L. \& Hogan, G.R. Laurence-MoonBiedl syndrome. Am J Dis Child 1973, 126: 119.

3. Hurley, R.M., Dery, P., Nogrady, M.B. \& Drummond, K.N. The renal lesions of the LaurenceMoon-Biedl syndrome. J Pediatr 1975, 87: 206-209.

4. Linne, T., Wikstad, I. \& Zetterstrom, R. Renal involvement in the Laurence-Moon-Biedl syndrome. Acta Paediatr Scand 1986, 75: 240-244.

5. McLoughlin, T.G. \& Shanklin, D.R. Pathology of the Laurence-Moon-Biedl syndrome. J Pathol Bacteriol 1967, 93: 65-79.

6. Nadjmi, B., Flanagan, M.J. \& Christian, J.R. Laurence-Moon-Biedl syndrome associated with multiple genito-urinary tract abnormalities. Am J Dis Child 1969, 117: 352.

7. Churchill, D.N., McManamon, P. \& Hurley, R.M. Renal disease: a sixth cardinal feature of the Laurence-Moon-Biedl syndrome. Clin Nephrol 1981, 16: $151-154$.

8. Teider, M., Levy, M., Gubler, M.C. Gagnadoux, J.R. \& Broyter, M. Renal abnormalities in the BardetBiedl syndrome. Int J Pediatr Nephrol 1982, 3: 199-203. the development of end stage renal failure with the aforementioned characteristic features lends support to the growing belief that with renal disease, the Laurence-Moon-Biedl syndrome has acquired a sixth and most prognostically significant cardinal feature. The excellent progress and good quality of life of these two patients suggests that patients can adapt well to maintenance dialysis therapy. A majority will require unit-based haemodialysis and therc appears to be no contra-indication to offering these patients a renal transplant although administration of the immunosuppression therapy would need supervision. For these reasons patients with Laurence-Moon-Biedl syndrome should be screened early for the presence of renal disease and referred for treatment.

9. Lee, W.J. \& Turetz, F. Laurence-Moon-Biedl syndrome, urographic observations. NY State J Med 1978, 78: 959.

10. Price, D., Gartner, J.G. \& Kaplan, B.S. Ultrastructural changes in the glomerular basement membrane of patients with the Laurence-Moon-Biedl syndrome. Clin Nephrol 1981, 16: 283-288.

11. Alton, D.J. \& McDonald, P. Urographic findings in the Bardet-Biedl syndrome. Radiology 1973, 109: 659.

12. Falkner, B., Langman, C. \& Katz, S. Renal histopathological changes in a child with the LaurenceMoon-Biedl syndrome. J Clin Pathol 1977, 30: 1077-1081.

13. Gokal, R., King, J., Bogle, S. et al. Outcome in patients on continuous peritoneal dialysis and haemodialysis; 4 year analysis of a prospective multicentre study. Lancet 1987, iii: 1105-1108. 